\title{
Acknowledgments and Notes on Sources
}

This project was made possible by the Killam Foundation and the Social Sciences Research Council of Canada. The Killam grant allowed me to devote two years entirely to the research necessary for completing this work.

The research primarily concentrated on the gamut of sources published in the USSR during the Gorbachev period. In addition, I was able to obtain important documents from a variety of sources in Russia. These include unpublished documents from the Communist Party Central Committee, the USSR Presidency of Gorbachev, and the Ministry of Foreign Affairs. Documents which were taken by Mikhail Gorbachev and his close associates are kept at the Gorbachev Foundation's Institute for the History of Perestroika, where they can be consulted with special authorization; they were used very extensively by Gorbachev and his assistants to write their respective memoirs. ${ }^{1}$ These documents, however, represent only a fraction of the archives relating to the Politburo and the presidency, which are currently in the Presidential Archives; in principle, these will not be accessible to the public for another twenty years.

To fill this gap, I conducted a large number of interviews between I 99 I and I 995 with many of the most important actors and with witnesses who had a particularly strategic view of the events in question. In

I. Except for those of Gorbachev and Cherniaev, the memoirs were published in Moscow, in very limited editions and with little circulation. Since they were based on scattered documents transferred to the institute, large periods of time and certain important events frequently get little or no attention. 
